\section{Dinucleotide repeat polymorphism at the D19S76 locus}

\author{
James L.Weber* and Paula E.May \\ Marshfield Medical Research Foundation, 510 \\ North St Joseph Avenue, Marshfield, WI 54449, \\ USA
}

Source/Description: A human genomic AluI fragment was cloned into $\mathrm{mp} 10$ and selected by hybridization to poly $(\mathrm{dC}-\mathrm{dA}) \cdot \operatorname{poly}(\mathrm{dG}-$ dT). The cloned fragment was designated Mfd37. Sequencing of Mfd37 provided the information necessary for polymerase chain reaction primer synthesis. The clone length was $211 \mathrm{bp}$, and the predicted length of the amplified fragment was $65 \mathrm{bp}$.

Primer Sequences: AAAAGTGTGTTACTTTCAGAAC (CA strand); ACAAGGTGACAAGGTGCCTA (GT strand).

Frequency: Estimated from 122 chromosomes of unrelated CEPH family grandparents (Caucasians). PIC $=0.40$.

$\begin{array}{ll}\text { Allele (bp) } & \text { Frequency } \\ 70 & 0.03 \\ 68 & 0.62 \\ 66 & 0.35\end{array}$

Chromosomal Localization: Assigned to chromosome 19 using DNA templates isolated from panels of somatic cell hybrids.

Mendelian Inheritance: Co-dominant segregation was observed in 40 two or three generation families.

Other Comments: Conditions for the amplification reactions were as described in the reference except that samples were processed through 27 temperature cycles consisting of $1 \mathrm{~min}$ at $94^{\circ}, 2 \mathrm{~min}$ at $55^{\circ}$ and $2 \mathrm{~min}$ at $72^{\circ}$. Sizes of the alleles were determined by comparison to mp8 DNA sequencing ladders and were the averages of the sizes of the GT-strand and CA-strand bands. The dinucleotide repeat sequence in $\mathrm{Mfd} 37$ was of the form (AC) ${ }_{10} \mathrm{~A}$. The sequence of $\mathrm{Mfd} 37$ has been submitted to GenBank.

Acknowledgements: This work was supported by the Marshfield Clinic and NIH grant GM41773.

Reference: Weber,J.L. and May,P.E. (1989) Am. J. Hum. Genet. 44, 388-396.

\section{Dinucleotide repeat polymorphism at the D1S104 locus}

\author{
James L.Weber*, Anne E.Kwitek and Paula \\ E.May \\ Marshfield Medical Research Foundation, 510 \\ North St Joseph Avenue, Marshfield, WI 54449, \\ USA
}

Source/Description: A human genomic Sau $3 A$ I fragment was cloned into mp19 and selected by hybridization to poly(dCdA) · poly(dG-dT). The cloned fragment was designated Mfd67. Sequencing of Mfd67 provided the information necessary for polymerase chain reaction primer synthesis. The clone length was $>242 \mathrm{bp}$, and the predicted length of the amplified fragment was $156 \mathrm{bp}$.

Primer Sequences: ATCCTGCCCTTATGGAGTGC (CA strand); CCCACTCCTCTGTCATTGTA (GT strand).

Frequency: Estimated from 116 chromosomes of unrelated CEPH family grandparents (Caucasians). PIC $=0.66$.

$\begin{array}{llll}\text { Allele (bp) } & \text { Frequency } & \text { Allele (bp) } & \text { Frequency } \\ 168 & 0.01 & 158 & 0.15 \\ 164 & 0.15 & 156 & 0.22 \\ 162 & 0.45 & 154 & 0.01 \\ 160 & 0.01 & 152 & 0.01\end{array}$

Chromosomal Localization: Assigned to chromosome 1 using DNA templates isolated from panels of somatic cell hybrids.

Mendelian Inheritance: Co-dominant segregation was observed in 15 two generation families.

Other Comments: Conditions for the amplification reactions were as described in the reference except that samples were processed through 27 temperature cycles consisting of $1 \mathrm{~min}$ at $94^{\circ}, 2 \mathrm{~min}$ at $55^{\circ}$ and $2 \mathrm{~min}$ at $72^{\circ}$. Sizes of the alleles were determined by comparison to mp8 DNA sequencing ladders. The most intense band for each allele on the denaturing polyacrylamide gels was used to determine allele size. The dinucleotide repeat sequence in Mfd67 was of the form $(\mathrm{TC})_{12}(\mathrm{AC})_{18}$. The sequence of Mfd67 has been submitted to GenBank.

Acknowledgements: This work was supported by the Marshfield Clinic and NIH grant GM41773.

Reference: Weber,J.L. and May,P.E. (1989) Am. J. Hum. Genet. 44, 388-396. 